\title{
Occupation du sol en Valloire
}

\section{Guillaume Varennes}

\section{OpenEdition \\ Journals}

Édition électronique

URL : http://journals.openedition.org/adlfi/3479

ISSN : 2114-0502

Éditeur

Ministère de la culture

Référence électronique

Guillaume Varennes, "Occupation du sol en Valloire », ADLFI. Archéologie de la France - Informations [En ligne], Rhône-Alpes, mis en ligne le 01 mars 2009, consulté le 01 mai 2019. URL : http://

journals.openedition.org/adlfi/3479

Ce document a été généré automatiquement le 1 mai 2019.

(c) Ministère de la Culture et de la Communication, CNRS 


\title{
Occupation du sol en Valloire
}

\author{
Guillaume Varennes
}

Identifiant de l'opération archéologique : 9014

Date de l'opération : 2009 (PT)

1 Une campagne de prospection géophysique inscrite au programme des activités de la prospection thématique triennale "Occupation du sol en Valloire» (2006-2008), a été réalisée par la société Géocarta Sarl durant l'été 2009, n'ayant pu être conduite en 2008 (voir BSR 2008). Deux secteurs ont été étudiés : le premier sur l'emprise de l'ensemble monumental de Champ-Martin et le second à l'est de l'ancien prieuré de Tourdan, au coeur du bourg antique.

2 À Champ-Martin, la continuité de la fosse de récupération du monument antique a pu être identifiée ainsi que le portique délimitant un espace vaste dont on ne saisit toujours pas les limites orientales et septentrionales (Fig. $n^{\circ} 1$ : Tourdan- Champ Martin prospection géophysique ARP). L'apport principal de cette opération est l'observation d'anomalies résistantes, immédiatement à l'est du monument, suggérant la présence de sols en dur encore conservés ou de fondations massives, qui peuvent être rattachées à l'ensemble monumental gallo-romain.

$3 \mathrm{Au}$ cœur du bourg, la prospection a permis de valider les orientations de voirie suggérées par les survols et les sondages menés en 2003 et 2004. Surtout, elle livre les premiers indices probants de l'organisation de ce secteur, structuré par le réseau routier. Deux voies délimitent un îlot vaste, où l'occupation antique paraît dense, au sein de laquelle l'hypothèse d'un complexe cultuel doit être soulevée si on retient la lecture de fana synchrones ou non (Fig. $\mathrm{n}^{\circ} 2$ : Tourdan- Les Roussières). Enfin, la complexité de lecture de certains secteurs où des anomalies résistantes ou conductrices ne peuvent être synchrones, selon l'interprétation proposée, suggère un potentiel stratigraphique intéressant dans un secteur où les ramassages de surface et les sondages permettent d'envisager une occupation continue du II ${ }^{\mathrm{e}}$ s. av. J.-C. au haut Moyen Âge. 


\section{ANNEXES}

Fig. $n^{\circ} 1$ : Tourdan- Champ Martin prospection géophysique ARP

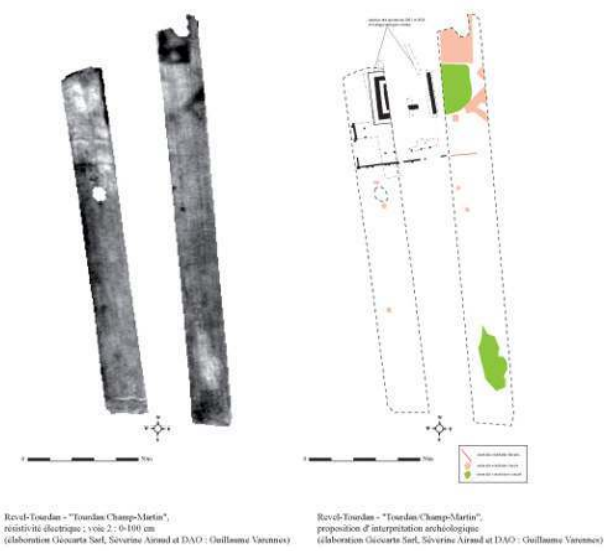

Revel-Tourdan, "Tourdan Champ-Martin" prospection géophysique ARP

Auteur(s) : Airaud, Séverine (Géocarta Sarl) ; Varennes, Guillaume (MCC). Crédits : G. Varenne et S. Airaud Géocarta Sarl (2009) 
Fig. $n^{\circ} 2$ : Tourdan- Les Roussières
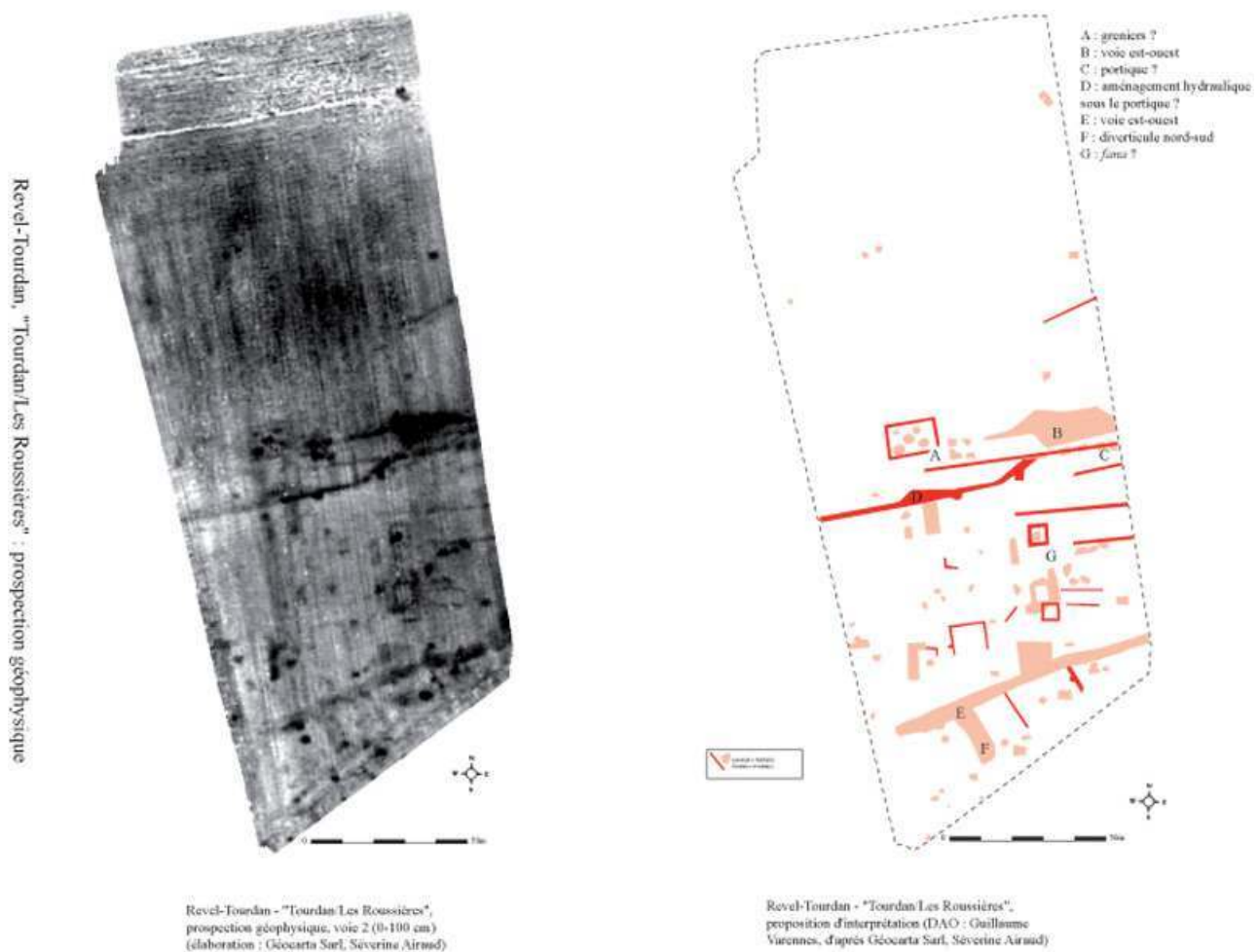

Auteur(s) : Airaud, Séverine (Géocarta Sarl) ; Varennes, Guillaume (MCC). Crédits : G. Varenne et S. Airaud Géocarta (2009)

INDEX

Index chronologique : Antiquité, Haut Moyen Âge, Moyen Âge

Thèmes : prospection géophysique

Index géographique : Rhône-Alpes, Isère, Revel-Tourdan

operation prospection thématique (PT)

\section{AUTEUR}

GUILLAUME VARENNES 